\title{
Electrochemical Behaviour and Differential Pulse Cathodic Adsorptive Stripping Voltammetric Determination of Carmustine
}

\author{
SACHIN DOI, PRIYANKA SINHA and D. K. SHARMA* \\ Electrochemical Sensor Research Laboratory, Department of Chemistry, \\ University of Rajasthan, Jaipur (Rajasthan)-302004, India \\ sharmadkuor@gmail.com
}

Received 30 November 2017 / Accepted 17 December 2017

\begin{abstract}
Electrochemical reduction properties of carmustine, an anticancer medication, were studied at glassy carbon electrode using cyclic voltammetry. A well defined irreversible reduction peak was obtained at $-1.001 \mathrm{~V}$ potential $v s$. $\mathrm{Ag} / \mathrm{AgCl}$ reference electrode in $\mathrm{BR}$ buffer of $\mathrm{pH} 6.3$. Mass transport in the reduction process was found to be diffusion controlled and a reduction mechanism was proposed on the basis of kinetic parameters which were calculated using experimental data. Furthermore, determination of carmustine in bulk form and human urine as a biological sample was carried out by differential pulse cathodic adsorptive stripping voltammetry using optimised parameters. Peak current was linear in the concentration range of $6.5 \times 10^{-6}$ $1.065 \times 10^{-3} \mathrm{M}$. LOD and LOQ were observed to be $4.16 \times 10^{-7} \mathrm{M}$ and $1.39 \times 10^{-6} \mathrm{M}$ respectively.
\end{abstract}

Keywords: Carmustine, Cyclic voltammetry, Differential pulse cathodic adsorptive stripping voltammetry, Diffusion-controlled, LOD and LOQ

\section{Introduction}

Carmustine, chemically 1,3-bis (2-chloroethyl)-1-nitrosourea (BCNU) is an alkylating and antineoplastic chemotherapy drug (Figure 1) used mainly for the treatment of malignant primary brain tumor and other cancers such as multiple myeloma, Hodgkin's disease, nonHodgkin's lymphomas, lung cancer and colon cancer ${ }^{1,2}$. BCNU is a lipophilic drug and lipophilicity enables it to cross the blood-brain barrier ${ }^{3}$. BCNU is a dialkylating agent i.e. it has two DNA binding sites through which it forms cross-linking between two bases of DNA. Cross-linking inhibits use of DNA as a template for further DNA and RNA synthesis i.e. now replication and transcription of DNA does not take place resulting in the death of cancerous tumour cell ${ }^{4}$. Systemic administration of BCNU is dose-limited because its high systemic administration can cause side effects such as hepatic toxicity, myelosuppression and pulmonary fibrosis. Therefore, BCNU-impregnated biodegradable polymer wafers $\left(\right.$ GLIADER $^{\mathrm{R}}$ ) are used for local delivery of $\mathrm{BCNU}^{5,6}$. 
<smiles>O=NN(CCCl)C(=O)NCCCl</smiles>

Figure 1. Chemical structure of carmustine

Since dosage of BCNU is very crucial to health therefore many analytical techniques have been introduced for its determination in pure form and biological samples such as reverse-phase HPLC, gas chromatography, electron capture detection, mass spectrometric detection $e t c^{1}$. But these methods are lengthy, tedious, involve time consuming sample preparation and extraction processes and require sophisticated and expensive instruments. Since BCNU has widespread use, therefore, its clinical and pharmacological studies require fast and sensitive analytical techniques for its assay in biological and pharmacological samples. Electrochemical techniques, especially polarography and voltammetric techniques are widely used in fundamental research for assay of drugs.

Critical literature survey revealed that $\mathrm{BCNU}$ has been studied and determined by voltammetry at hanging mercury drop electrode, mercury meniscus modified silver solid amalgam electrode ( $m$-AgSAE), polarography (DCP, DPP and NPP) ${ }^{1}$. Since voltammetry is a simple, sensitive, selective, fully validated, low-cost technique with good precision, accuracy and good limit of detection and does not require sample pre-treatment or any time consuming extraction steps prior to assay of drugs in dosage forms. Therefore, voltammetry might be alternative to the lengthy and time consuming methods for the assay of the drug. To the best of our knowledge, till date, no information has been reported about detailed electrode kinetic studies of BCNU and quantitative voltammetric determination of BCNU with glassy carbon electrode (GCE) in dosage forms or in human urine. Thus the aim of this work is to investigate electrochemical behavior and possible reduction mechanism of BCNU with GCE by cyclic (CV) and differential pulse cathodic adsorptive stripping (DPCAdSV) voltammetric techniques for direct determination of BCNU.

\section{Experimental}

All electrochemical measurements were recorded using model 1230 A [SR 400] (CHI instrument, Bee Cave, TX, USA) electrochemical analyzer. A cell system configured with three electrodes (glassy carbon as working electrode, $\mathrm{Pt}$ as a counter electrode and $\mathrm{Ag} / \mathrm{AgCl}$ as reference) was used for all measurements. Controlled potential coulometric experiments were performed on model 760 electrochemical workstation (CHI Instrument). All pH measurements were made on CHINO digital $\mathrm{pH}$ meter fitted with a glass electrode which was previously standardized with buffers of known $\mathrm{pH}$. All experiments were performed at the standard temperature of $25^{\circ} \mathrm{C}$.

\section{Materials and methods}

Carmustine was purchased from Emcure Pharmaceuticals Ltd. under the trade name consium in its pure and anhydrous form. A standard stock solution of $3 \times 10^{-3} \mathrm{M}$ concentration of carmustine was prepared by dissolving $0.016 \mathrm{~g}$ of the drug in $25 \mathrm{~mL}$ distilled ethanol. Double distilled water, obtained from laboratory distillation assembly was used to prepare Britton-Robinson (BR) buffer solution of different $\mathrm{pH}$ and $\mathrm{KCl}(1 \mathrm{M})$ solution as supporting electrolyte and used throughout the voltammetric study. All chemicals used were of analytical grade quality (purchased from Sigma-Aldrich) and used without further purification. 
All solutions were protected from sunlight and stored at $4{ }^{\circ} \mathrm{C}$ in a refrigerator to avoid decomposition. Before use, all solutions were left to attain room temperature $\left(25^{\circ} \mathrm{C}\right)$.

Working solutions for recording voltammetric measurements were prepared by mixing aliquot (appropriate volume) of the standard stock solution of drug, $9 \mathrm{~mL} \mathrm{BR}$ buffer and $1 \mathrm{M}$ $\mathrm{KCl}$ solution in the voltammetric cell. The effective concentration (E.C.) of the solution in the cell was determined using the formula

E.C $=\frac{\text { Conc. }(\mathrm{M}) \text { of stock drug solution } \times \text { Volume of stock drug solution added in the cell }}{\text { Tot }}$ Total volume of solution in the cell

All concentrations mentioned throughout the research paper are in terms of E.C.

\section{Preparation of spiked urine samples}

Drug-free human urine was obtained from healthy volunteers and was stored frozen until assay. Aliquots of urine and carmustine stock solution of bulk were mixed into series of centrifugation tubes to get the final concentration. All the solutions were vortexed for $3 \mathrm{~min}$ using a vortex mixer and then subjected to centrifugation for $10 \mathrm{~min}$ at $5000 \mathrm{rpm}$ to get rid of residues. The supernatant of all centrifuge tubes was quantitatively transferred into $10 \mathrm{~mL}$ measuring flasks. Working solutions for voltammetric studies were prepared by adding BR buffer solution into measuring flasks and then the content of flasks were transferred into the voltammetric cell.

\section{Pretreatment of glassy carbon electrode and voltammetric procedure}

Glassy carbon electrode was polished with $0.08 \mu \mathrm{m}$ Alumina slurry in water to furnish reproducible electrode surface and to improve sensitivity and resolution of voltammetric peaks before each voltammetric measurement. Then GCE surface was washed with double distilled water and subjected to sonication for $40 \mathrm{~s}$ to remove any alumina if remained onto the electrode surface. After that, it was allowed to dry in an oven at $30{ }^{\circ} \mathrm{C}$ for $2 \mathrm{~min}$. Before each voltammetric measurement, a continuous stream of nitrogen (Instrumental Grade; $99.999 \%$ pure) was passed for $10 \mathrm{~min}$ through the cell to deoxygenize the solution in it.

\section{Results and Discussion}

\section{Electrochemical behavior of carmustine}

The electrochemical studies of BCNU were carried out using cyclic voltammetry (CV), differential pulse cathodic adsorptive stripping voltammetry (DPCAdSV) and controlled potential coulometry (CPC). BCNU gave a well defined irreversible reduction in all its electrochemical measurements at GCE in BR buffer of $\mathrm{pH} 6.3$.

\section{Cyclic voltammetric behavior}

In cyclic voltammetric studies of $\mathrm{BCNU}$, when a potential window of $-0.3 \mathrm{~V}$ to $-1.3 \mathrm{~V}$ versus $\mathrm{Ag} / \mathrm{AgCl}$ reference electrode was applied, a well defined reduction peak was observed at $1.001 \mathrm{~V}$ in BR buffer of $\mathrm{pH} 6.3$ at GCE.

\section{Effect of scan rate}

Effect of scan rate was studied at peak current (Ip) and peak potential (Ep) under above mentioned experimental conditions. It was observed that when scan rate increased from $60 \mathrm{mV} / \mathrm{s}$ to $200 \mathrm{mV} / \mathrm{s}$, at $4.6 \times 10^{-4} \mathrm{M}$ of BCNU, peak potential shifted towards more negative direction with increasing peak current (Figure 2) confirming the irreversible nature of reduction process ${ }^{7}$. When peak current (Ip) was plotted against square root of scan rate $\left(v^{1 / 2}\right)$ a straight line was obtained following the Randles-Sevcik equation. 


$$
\operatorname{Ip}=\left(2.99 \times 10^{5}\right) n\left[\alpha n^{\prime}\right]^{1 / 2} \mathrm{~A} \mathrm{C}_{\mathrm{o}} \mathrm{D}_{\mathrm{o}}^{1 / 2} v^{1 / 2}
$$

Where $\mathrm{n}$ is the number of electrons exchanged in reduction, $\mathrm{n}$ ' is the number of electrons involved in the rate determining step of the electrode process, $\alpha$ is the charge transfer coefficient, $\mathrm{A}\left(\mathrm{cm}^{2}\right)$ is cross sectional area of the electrode, $\mathrm{C}_{\mathrm{o}}\left(\mathrm{mol} / \mathrm{cm}^{3}\right)$ is the concentration of the electroactive species in the bulk solution, $\operatorname{Ip}(\mathrm{A})$ is the cathodic peak current, $\mathrm{D}_{\mathrm{o}}\left(\mathrm{cm}^{2} \mathrm{~s}^{-1}\right)$ is the diffusion coefficient of the electro active species being reduced and $v\left(\mathrm{Vs}^{-1}\right)$ is the scan rate ${ }^{8}$ and the corresponding linear regression $\left(\mathrm{r}^{2}=0.996\right)$ equation of plot between Ip $v s . v^{1 / 2}$ in Figure 3 is expressed as:

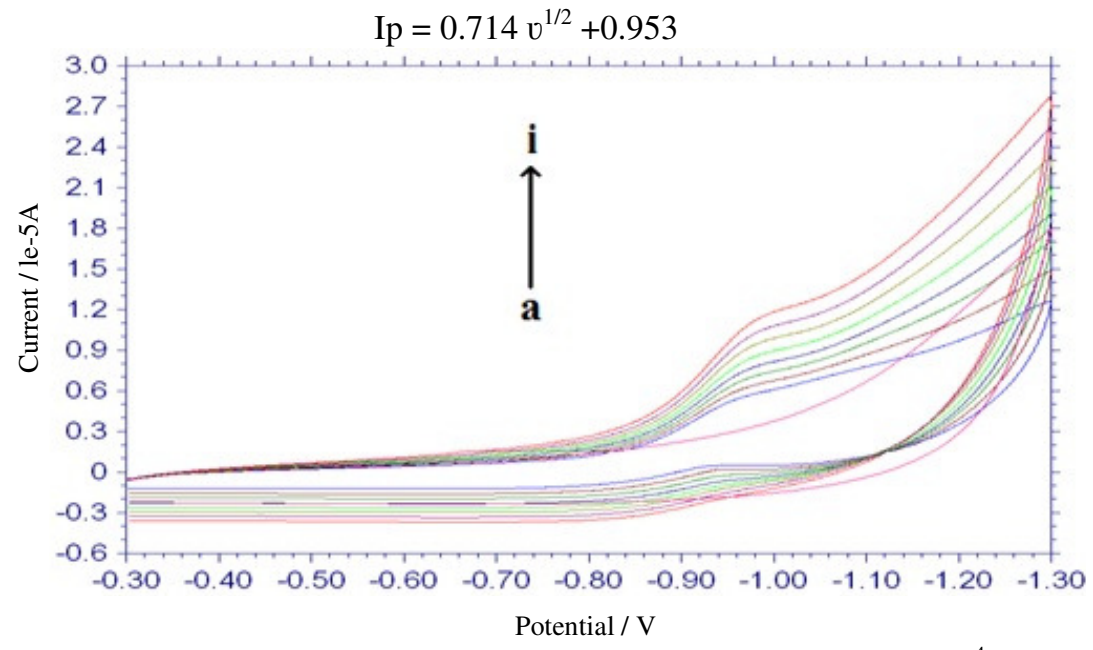

Figure 2. Cyclic voltammograms of carmustine (Concentration $4.6 \times 10^{-4} \mathrm{M}$ ) at different scan rates (a) blank (b) $60 \mathrm{mV} / \mathrm{s}$ (c) $80 \mathrm{mV} / \mathrm{s} \mathrm{(d)} 100 \mathrm{mV} / \mathrm{s}$ (e) $120 \mathrm{mV} / \mathrm{s}$ (f) $140 \mathrm{mV} / \mathrm{s}$ (g) $160 \mathrm{mV} / \mathrm{s}$ (h) $180 \mathrm{mV} / \mathrm{s} \mathrm{(i)} 200 \mathrm{mV} / \mathrm{s}$ at pH 6.3 in BR buffer

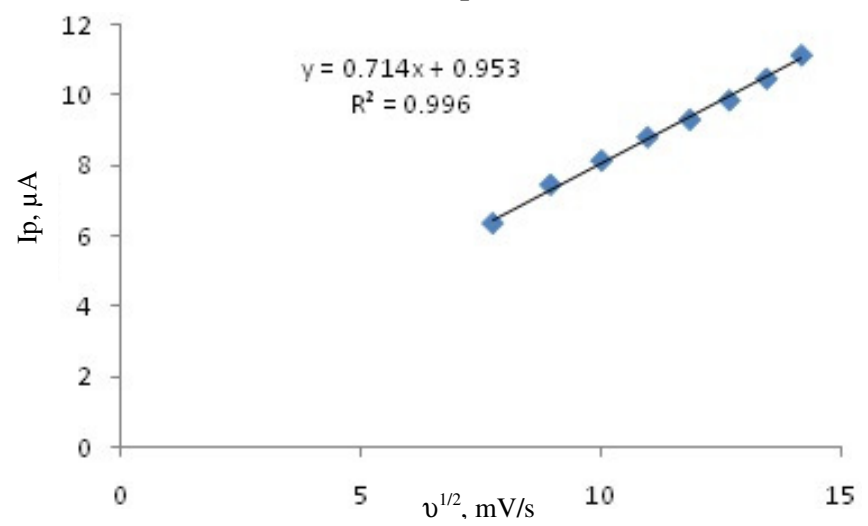

Figure 3. Plot of peak current (Ip) versus square root of scan rate $\left(v^{1 / 2}\right)$ from voltammogram in Figure 2 for carmustine in $4.6 \times 10^{-4} \mathrm{M}$ concentration in BR Buffer of $\mathrm{pH} 6.3$

A straight line of Randles-Sevcik plot suggested that diffusion was the means of mass transport in reduction process, which was further confirmed ${ }^{9-11}$ by plotting $\log$ Ip $v s . \log v$ (Figure 4). A straight line was obtained and corresponding linear regression $\left(r^{2}=0.996\right)$ equation is expressed as:

$$
\log (\mathrm{Ip})=0.445 \log v+0.018
$$




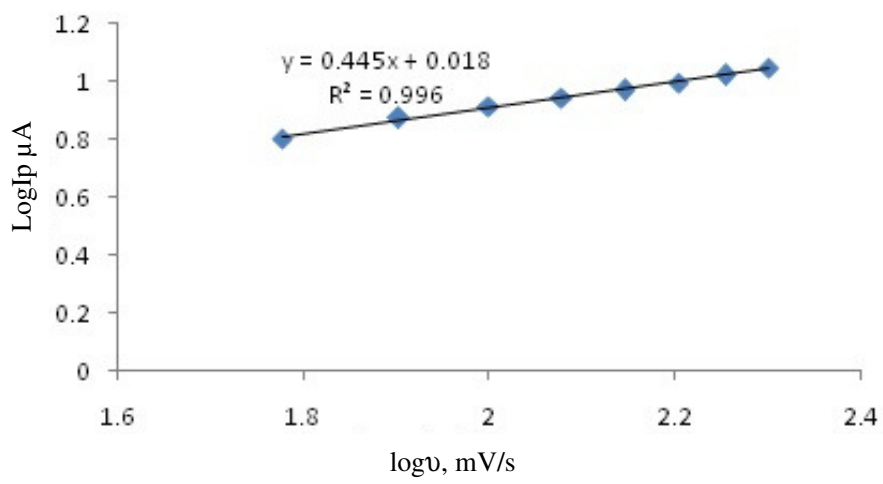

Figure 4. Logarithmic plot of peak current $(\log \mathrm{Ip})$ versus logarithm of scan rate $(\log v)$ from voltammogram in Figure 2 for Carmustine in $4.6 \times 10^{-4} \mathrm{M}$ concentration in BR buffer of $\mathrm{pH} 6.3$

The obtained slope of 0.445 was very close to the theoretical value of 0.5 for a diffusion controlled process which confirmed the diffusion controlled nature of reduction process ${ }^{12,13}$.

\section{Determination of surface area and reduction mechanism}

To calculate the effective surface area of glassy carbon electrode cyclic voltammogram of $1 \mathrm{mM} \mathrm{K}{ }_{3} \mathrm{Fe}(\mathrm{CN})_{6}$ solution at $100 \mathrm{mV} / \mathrm{s}$ scan rate was recorded using $0.1 \mathrm{M} \mathrm{KCl}$ as the supporting electrolyte. For the reversible redox couple $\mathrm{Fe}(\mathrm{CN})_{6}{ }^{3-} / \mathrm{Fe}(\mathrm{CN})_{6}{ }^{4-}$ the peak potentials were found at 0.195/0.259 at GCE. Using Randles-Sevcik equation effective surface area of GCE was found to be $0.0851 \mathrm{~cm}^{2}$. Values of diffusion coefficient $\left(D_{0}\right)$ and total number of electrons ( $\mathrm{n}$ ) were taken as $7.6 \times 10^{-6} \mathrm{~cm}^{2} / \mathrm{s}$ and 1 respectively ${ }^{14}$.

\section{Kinetics of reduction of Carmustine}

Determination of parameter [ $\left.\alpha n^{\prime}\right]$

To study the reduction kinetics of BCNU the value of $\alpha$ ' required to be calculated and it was done by plotting graph of Ep vs. logv. A straight line was obtained according to the following equation (Figure 5):

$$
E_{p}=E^{0}-\frac{R T}{a n^{\prime} F}\left[0.78+\ln \left(\frac{D_{o}^{1 / 2}}{K_{s}}\right)-0.5 \ln \frac{R T}{a n^{\prime} F}\right]-\left(\frac{R T}{2 a n^{\prime} F}\right) \ln v
$$

Where, $E_{p}(V)$ is peak potential, $E^{o}(V)$ is formal potential, $\alpha$ is the cathodic electron transfer coefficient, $\mathrm{T}(\mathrm{K})$ is temperature, $\mathrm{k}_{\mathrm{s}}$ is heterogeneous rate constant, $\mathrm{n}$ ' is number of electrons involved in the rate determining step, and $\mathrm{F}$ is the Faraday and rest parameters have their usual meanings ${ }^{15,16}$.

Straight line of Ep vs. log $v$ plot is expressed by the following linear regression equation:

$$
\text { Ep }=0.035 \log v+0.888 \quad r^{2}=0.990
$$

The value of $\alpha$ n' was calculated by comparing slope of equations 4 and 5 and was found equal to 0.84 .

Value of $\alpha$ ' was also calculated by plotting $\operatorname{lnIp} v s$. Ep- $\mathrm{E}^{0}$ (Figure 6) according to the equation:

$$
\mathrm{Ip}=0.227 \mathrm{nFACk} \mathrm{e}^{0}\left[-\alpha \mathrm{n}^{\prime} \mathrm{F}\left(\mathrm{Ep}-\mathrm{E}^{\mathrm{o}}\right) / \mathrm{RT}\right]
$$

Where $\mathrm{E}^{0}$ is formal potential $(\mathrm{V}), \mathrm{k}^{0}$ is standard heterogeneous rate constant and rest parameters have their usual meanings. 


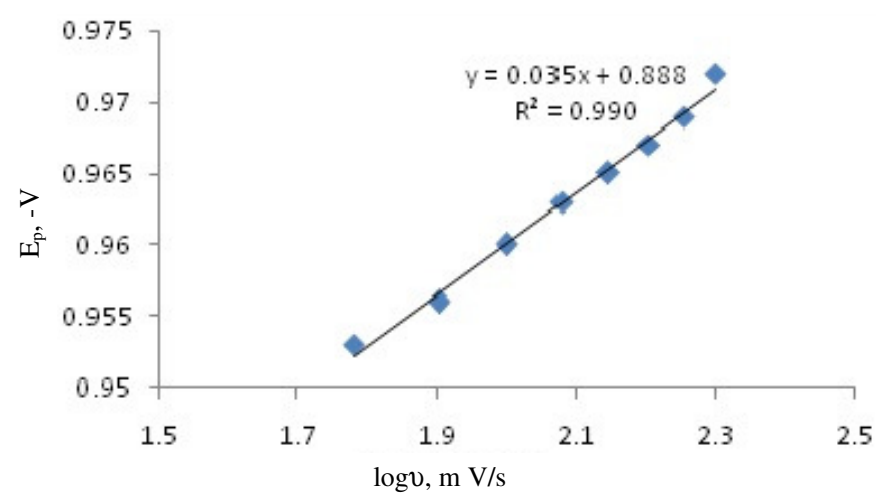

Figure 5. Plot of peak potential $\left(\mathrm{E}_{\mathrm{p}}\right)$ versus logarithm of scan rate (logv) for carmustine in $4.6 \times 10^{-4} \mathrm{M}$ concentration in BR Buffer of $\mathrm{pH} 6.3$

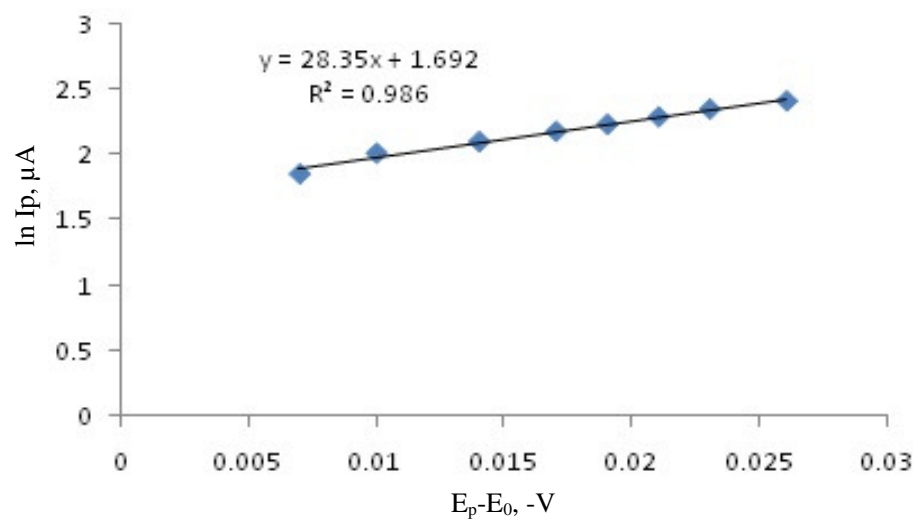

Figure 6. Plot of $\operatorname{lnIp}$ versus Ep-Eo for Carmustine in $4.6 \times 10^{-4} \mathrm{M}$ concentration in BR Buffer of $\mathrm{pH} 6.3$

A straight line was obtained and the linear regression equation of $\ln \mathrm{Ip} v s . \mathrm{Ep}^{\mathrm{E}} \mathrm{E}^{0}$ plot is expressed as:

$$
\ln \mathrm{Ip}=28.35\left(\mathrm{E}_{\mathrm{p}}-\mathrm{E}^{0}\right)+1.692 \quad \mathrm{r}^{2}=0.986
$$

From equations 5 and 6 values of slope were compared to calculate $\alpha$ ' and it was found equal to 0.73 . Thus values of $\alpha$ ', calculated by above two processes were found nearly same and an average value of 0.79 was used for further calculations.

\section{Determination of total number of electrons}

The total number of electrons (n) involved in overall reduction process was calculated by analyzing the charge consumed by desired concentration of BCNU. This was accomplished by taking $5 \mathrm{~mL}$ of $4 \mathrm{mg} \mathrm{mL}^{-1}$ solution of BCNU in a cell and electrolysis was performed at a potential of $-1.001 \mathrm{~V}$ against $\mathrm{Ag} / \mathrm{AgCl}$ reference electrode for 9 hours. During the electrolysis, solutions were kept stirred and purged with nitrogen. Due to long-time electrolysis, current efficiency and completion of electrolysis were assumed to be nearly $100 \%$ and $99.99 \%$ respectively. The total number of electrons (n) involved in overall reduction process was calculated using the formula $\mathrm{Q}=\mathrm{nFN}$, where $\mathrm{Q}$ is charge in coulombs, $\mathrm{N}$ is number of moles of BCNU and $\mathrm{F}$ is Faraday's constant. The value of $\mathrm{n}$ was found to be 2 for BCNU at GCE. 
Determination of diffusion coefficient $\left(D_{o} \mathrm{~cm}^{2} / \mathrm{s}\right)$

Diffusion coefficient of BCNU for reduction at GCE was calculated using Randles-Sevcik equation at scan rates of $200 \mathrm{mV} / \mathrm{s}, 180 \mathrm{mV} / \mathrm{s}, 160 \mathrm{mV} / \mathrm{s}, 140 \mathrm{mV} / \mathrm{s}, 120 \mathrm{mV} / \mathrm{s}, 100 \mathrm{mV} / \mathrm{s}$, $80 \mathrm{mV} / \mathrm{s}$ and $60 \mathrm{mV} / \mathrm{s}$ when $\mathrm{n}=2, \alpha \mathrm{n}^{\prime}=0.79, \mathrm{~A}=0.0851 \mathrm{~cm}^{2}$ and $\mathrm{C}=4.6 \times 10^{-7} \mathrm{~mol} / \mathrm{cm}^{3}$. Mean value of diffusion coefficients at above mentioned scan rates was taken and it came out equal to $1.49 \times 10^{-6} \mathrm{~cm}^{2} / \mathrm{s}$.

\section{Effect of $p H$}

Effect of $\mathrm{pH}$ on peak current and peak potential response of BCNU was studied in $\mathrm{pH}$ range of 2.8 to 7.7 at GCE. Reduction of BCNU took place under acidic medium and accompanied by proton transfer in the rate determining step. The absence of peak response lower than $\mathrm{pH}$ 2.8 might be explained by the fact that at $\mathrm{pH}$ lower than 2.8 peak potential corresponding to the reduction of BCNU is much negative than the hydrogen evolution potential at GCE and at $\mathrm{pH}$ values higher than 7.7 absence of peak response to the applied porential might be due to inactivity of BCNU. pH 6.3 was optimized on the basis of peak height, peak symmetry and peak shape (Figure 7) and was used for the voltammetric study of BCNU.

The plot of peak potential (Ep) vs.pH was linear and linear regression equation of the plot is expressed as (Figure 8):

$$
\mathrm{Ep}=-0.054 \mathrm{pH}-0.562 \quad \mathrm{r}^{2}=0.992
$$

The slope value of (Ep) vs. $\mathrm{pH}$ plot was found equal to $54 \mathrm{mV}$ which was very close to the theoretical value of $60 \mathrm{mV}$ suggesting that number of electrons and protons involved in the reduction process of BCNU at glassy carbon electrode were equal ${ }^{17,18}$.

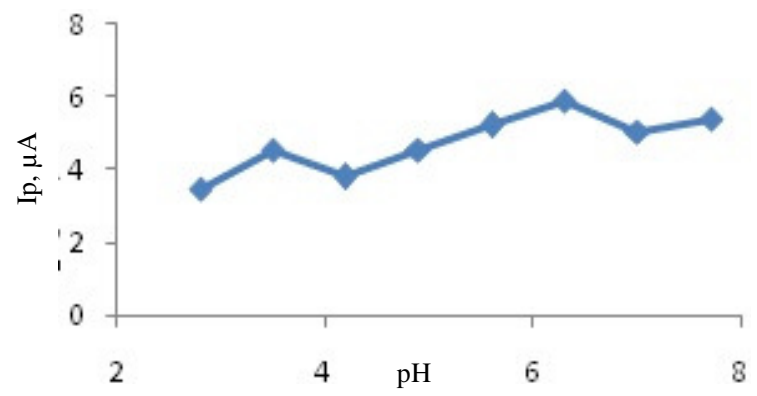

Figure 7. Optimization of $\mathrm{pH}$

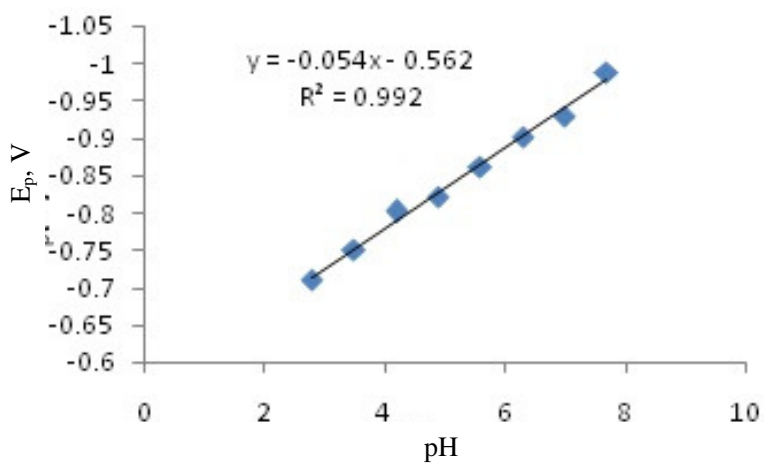

Figure 8. Plot of peak potential $\left(\mathrm{E}_{\mathrm{p}}\right)$ vs. $\mathrm{pH}$ of $4.6 \times 10^{-4} \mathrm{M}$ carmustine solution 


\section{Proposed reduction mechanism}

On the basis of $\mathrm{pH}$ and $\mathrm{CPC}$ studies, it was concluded that 2 electrons and 2 protons were participating in the reduction process of BCNU. A reduction mechanism was proposed based on all experimental observations (Scheme 1):

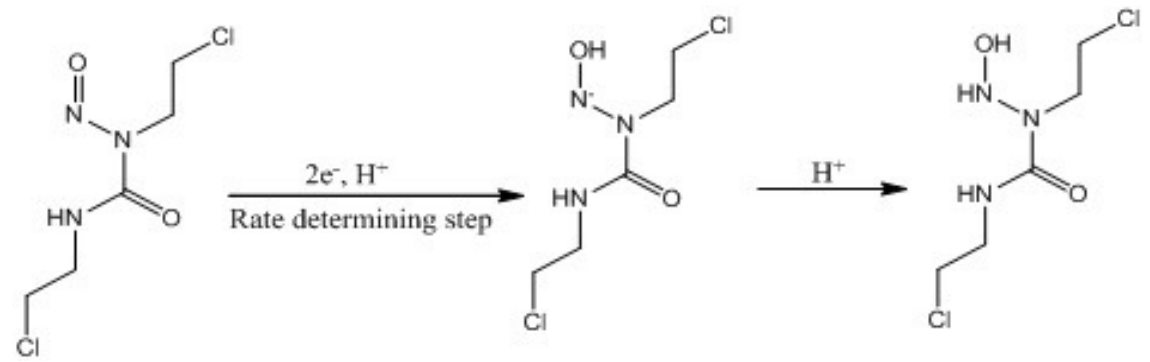

Scheme 1. Proposed reduction mechanism of carmustine

\section{Electroanalytical determination of carmustine}

Since voltammetric methods have cost-effectiveness high accuracy, precision, sensitivity and absence of lengthy extraction processes, therefore, they are widely used for analytical purposes. In the present paper, differential pulse cathodic adsorptive stripping voltammetric technique was optimized for the determination of BCNU in bulk form and in human urine at GCE.

\section{Optimization of parameters}

Operational parameters such as accumulation time $\left(\mathrm{t}_{\mathrm{acc}}\right)$, accumulation potential $\left(\mathrm{E}_{\mathrm{acc}}\right)$, scan increment $(\Delta S)$, peak to peak amplitude, pulse amplitude $\left(E_{\mathrm{sw}}\right)$, pulse period and pulse width etc. were optimized before recording DPCAdS voltammograms to get best response in terms of peak shape, peak current, peak height and peak stability. The optimized parameters are given in Table 1.

Table 1. The optimized experimental parameters of DPCAdSV procedure

\begin{tabular}{cc}
\hline Optimized operational parameters for DPCAdSV \\
\hline Scan increment, $\mathrm{mV}$ & 04 \\
Pulse amplitude, $\mathrm{mV}$ & 50 \\
Deposition time (s) & 15 \\
Deposition potential (V) & 0 \\
Pulse width (s) & 0.2 \\
Pulse period (s) & 0.5 \\
\hline
\end{tabular}

\section{Effect of concentration}

Determination of BCNU in bulk formulations was carried out using DPCAdSV method. Peak current was linearly dependent on the concentration of BCNU within the concentration range of $6.5 \times 10^{-6}-1.065 \times 10^{-3} \mathrm{M}$ (Figure 9). When peak current (Ip) was plotted against concentration (M), over which linearity was found, a straight line was obtained (Figure 10) and corresponding linear regression equation is:

$$
\mathrm{Ip}=3.088 \mathrm{E}+03 \text { Conc }+0.218 \quad \mathrm{r}^{2}=0.989
$$




\section{Validation of analytical procedure}

Validation of the proposed method for determination of BCNU in bulk form was carried out by limit of detection (LOD), limit of quantification (LOQ), \% recovery, linearity range of concentration, ruggedness and robustness.

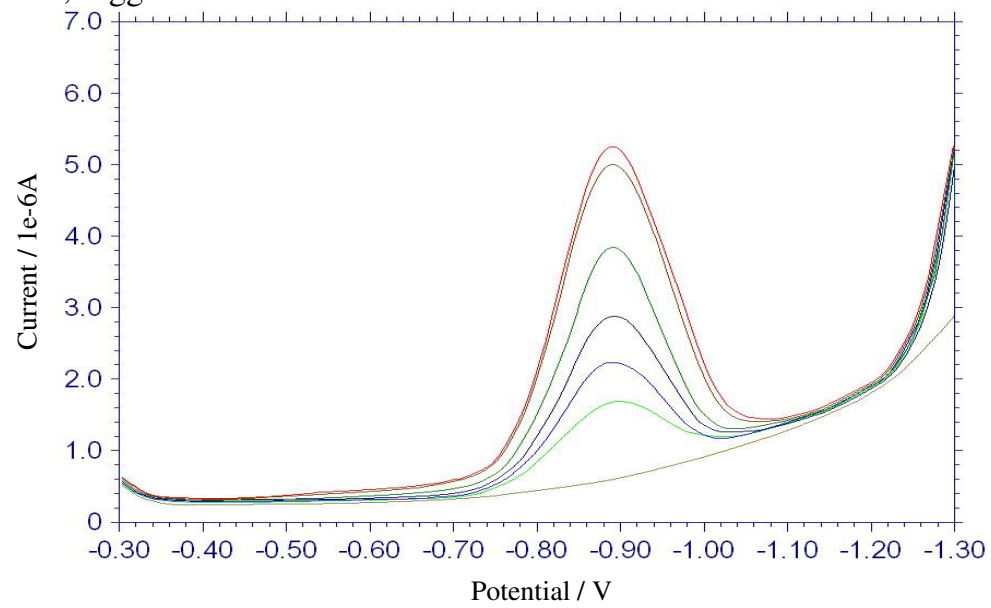

Figure 9. DPCAdS voltammogram of carmustine at different concentrations in bulk form in BR buffer at $\mathrm{pH} 6.3$

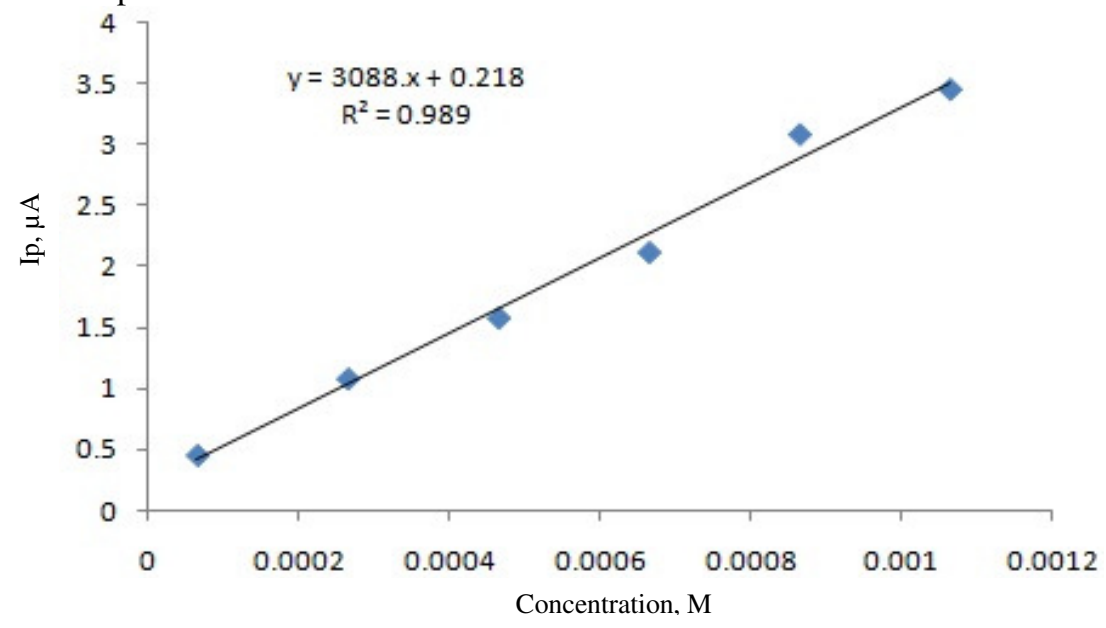

Figure 10. Plot of peak current $\left(\mathrm{I}_{\mathrm{p}}\right)$ versus Concentration $(\mathrm{C})$ from voltammogram in Figure 9 of carmustine with varying concentrations in BR Buffer of $\mathrm{pH} 6.3$

\section{Limit of detection (LOD) and limit of quantification}

Limit of detection (LOD) and limit of quantification (LOQ) were calculated using equations $\mathrm{LOD}=3 \mathrm{~S} / \mathrm{m}$ and $\mathrm{LOQ}=10 \mathrm{~S} / \mathrm{m}$ respectively, where $\mathrm{s}$ is the standard deviation of intercept of the calibration curve and $\mathrm{m}$ is the slope of the calibration curve $\mathrm{e}^{19-21}$ (Ip vs. concentration). Low values of LOD and LOQ indicated about good sensitivity of the voltammetric method. Likewise, a low value of \%RSD indicated less spread of data that is good precision of the method. All data are listed in Table 2. 
Table 2. Analytical parameters for voltammetric determination of carmustine in bulk form using DPCAdSV at bare GCE

\begin{tabular}{cc}
\hline Parameters & Results \\
\hline Measure potential, $\mathrm{V}$ & -0.892 \\
Linearity range, $\mathrm{M}$ & $6.5 \times 10^{-6}-1.065 \times 10^{-3}$ \\
Slope, $\mu \mathrm{A} / \mathrm{mol} / \mathrm{L}$ & $3.088 \times 10^{3}$ \\
Intercept, $\mu \mathrm{A}$ & 0.218 \\
Correlation coefficient & 0.989 \\
LOD, mol/L & $4.16 \times 10^{-7}$ \\
LOQ, mol/L & $1.39 \times 10^{-6}$ \\
SD & 0.000428 \\
Repeatability, \%RSD & 0.839 \\
\hline
\end{tabular}

$R S D=$ Relative standard deviation

\section{Accuracy and precision}

Linearity range of the DPCAdSV method at GCE was used to study accuracy and precision of the proposed method. For this purpose, a certain amount of stock solution of BCNU was added and corresponding \% recoveries were determined. Amount of BCNU found was very close to the amount of BCNU actually added indicating about good accuracy and low value of \% RSD ( $\mathrm{n}=5)$ confirmed good precision of the proposed method. Results for accuracy and precision are listed below in Table 3.

Table 3. Result of accuracy and precision for assay of carmustine in bulk form using DPCAdSV at GCE

\begin{tabular}{ccccc}
\hline S.No. & Amount added, $\mathrm{mg} / \mathrm{L}$ & *Mean recovery & SD & \%RSD \\
\hline 1 & 10 & $9.997 \pm 0.015$ & 0.012 & 0.12 \\
2 & 20 & $19.993 \pm 0.024$ & 0.019 & 0.095 \\
3 & 30 & $30.006 \pm 0.045$ & 0.036 & 0.12 \\
\hline
\end{tabular}

*The data were collected based on the five separate $(n=5)$ determinations. Average for five determination process and recovery values are given as mean \pm ts/ $/$ n (at $95 \%$ confidence level)

Application of analytical determination to spiked human urine samples

The significance of the proposed method was examined by employing it for the determination of carmustine in spiked urine as a biological sample. Without any requirement of timeconsuming extraction or evaporation step for sample preparation the proposed method can be applied simply after dilution step with direct measurements in acidic media. Results of the analytical study of spiked urine are summarized in Table $4 \& 5$.

Table 4. Recovery results of proposed method for spiked human urine samples (solution of standard carmustine was spiked)

\begin{tabular}{ccccc}
\hline Sample & Amount added, mg/L & Amount found, mg/L & Recovery $^{\mathrm{a}}$ & \%RSD \\
\hline & & 19.20 & & \\
Standard in & \multirow{2}{*}{20} & 19.38 & $19.696 \pm 0.31$ & \\
urine sample & & 19.50 & $\mathrm{t}_{\text {cal }}=2.719$ & 1.27 \\
& & 20.10 & $\mathrm{t}_{\text {tab }}=2.776$ & \\
\hline
\end{tabular}

\footnotetext{
${ }^{a}$ Results of recovery values are given as mean $\pm t s / \sqrt{ } n$ (at $95 \%$ confidence level)
} 
Table 5. Recovery results of proposed method for spiked human urine samples (solution of Carmustine was spiked)

\begin{tabular}{ccccc}
\hline Sample & Amount added, mg/L & Amount found, mg/L & Recovery $^{\mathrm{a}}$ & $\%$ RSD \\
\hline & & 15.33 & & \\
Carmustine in & 10 & 15.43 & $15.27 \pm 0.41$ & \\
urine sample & 15.65 & $\mathrm{t}_{\text {cal }}=1.83$ & 2.16 \\
& & 14.77 & $\mathrm{t}_{\text {tab }}=2.78$ & \\
\hline
\end{tabular}

${ }^{a}$ Results of recovery values are given as mean $\pm t s / \sqrt{ } n$ (at $95 \%$ confidence level)

\section{Conclusion}

Electrochemical behavior of anti-cancer medication carmustine (BCNU) was studied at glassy carbon electrode, using CV and DPCAdSV technique, in bulk formulation. It was found that reduction process of $\mathrm{BCNU}$ was irreversible, diffusion controlled and $\mathrm{pH}$ dependent. Furthermore, kinetic parameters such as diffusion coefficient $\left(\mathrm{D}_{\mathrm{o}}\right)$, number of electrons (n) and electron transfer coefficient $(\alpha)$ were also calculated which were used to propose reduction mechanism. DPCAdSV method was employed for the determination of $\mathrm{BCNU}$ in a urine sample as a biological sample.

The proposed method is direct, simple, cost-effective, requires only small amount of analyte and does not involve tedious steps such as separation, filtration, extraction, evaporation $e t c$., required by chromatographic methods. Furthermore, the proposed method has good operational characteristics such as extremely low values of detection limits, sensitivity, selectivity, wide liner working range and exhibit good accuracy, precision and repeatability for determination of BCNU in bulk as well as in urine as a biological sample.

\section{Acknowledgment}

This work is financially supported by the Council of Scientific and Industrial Research, New Delhi, India, by grant File Number 09/149(0680)/2016/EMR-I.

\section{References}

1. Pecková K, Vrzalová L, Bencko V and Barek J, Collect Czech Chem Commun., 2009, 74(11-12), 1697-1713; DOI:10.1135/cccc2009112

2. Meulemans A, Giroux B, Hannoun P, Robine D and Henzel D, Chemotherapy, 1991, 37(2), 86-92; DOI:10.1159/000238838

3. Meulemans A, Giroux B, Hannoun P, Henzel D, Bizzari J P and Mohler J, Chemotherapy, 1989, 35(5), 313-319; DOI:10.1159/000238687

4. Sirajuddin M, Ali S and Badshah A, J Photochem Photobiol B, Biol., 2013, 124, 1-19; DOI:10.1016/j.jphotobiol.2013.03.013

5. Li Y, Duc H L H, Tyler B, Williams T, Tupper M, Langer R, Brem H and Cima M J, J Control Release, 2005, 106(1-2), 138-145; DOI:10.1016/j.jconrel.2005.04.009

6. Kuo Y C and Wang C C, J Taiwan Inst Chem Eng., 2015, 46, 1-14; DOI:10.1016/j.jtice.2014.08.035

7. Nicholson R S, Anal Chem., 1965, 37(11), 1351-1355; DOI:10.1021/ac60230a016

8. Bard A J and Faulkner L R, Electrochemical Methods: Fundamentals and Applications, $2^{\text {nd }}$ Ed., John Wiley and Sons Inc, New York, 2006. 
9. Muñoz E, Camacho L, Avila J L and Blanco F G, Analyst, 1989, 114, 1611-1615; DOI:10.1039/AN9891401611

10. Sharma D K, Andreas O, Anthony P O M and Bhargava S K, Colloids Surf A, 2011, 386(1-3), 98-106; DOI:10.1016/j.colsurfa.2011.07.001

11. Gosser D K, Cyclic Voltammetry: Simulation and Analysis of Reaction Mechanisms, VCH: New York, 1994.

12. Elqudaby H M, Arab J Chem., 2013, 6, 327-333; DOI:10.1016/j.arabjc.2011.05.019

13. Kumari M and Sharma D K, J Korean Chem Soc., 2011, 55(1), 50-56.

14. Goyal R N, Rana A R, Aziz M A and Oyama M, Analytica Chimica Acta, 2011, 693(1), 35-40; DOI:10.1016/j.aca.2011.03.026

15. Niu X, Yan L, Wen Z, Li X, Niu Y, Lu Y and Sun W, Anal. Lett., 2017, 50(2), 325335; DOI:10.1080/00032719.2016.1177536

16. Kissinger $\mathrm{P} \mathrm{T}$ and Heineman $\mathrm{W}$ R, Laboratory Techniques in Electroanalytical Chemistry, Marcel Dekker: New York, 1996.

17. Tasdemir I H, Akay M A, Erk N and K1lıc E, Electroanalysis. 2010, 22(17-18), 21012109; DOI:10.1002/elan.201000100

18. Jain R and Sharma R, J Electrochem Soc., 2013, 160(8), H489-H493; DOI:10.1149/2.105308jes

19. Sinha P, Shekhawat A and Sharma D K, Rep Electrochem., 2015, 5, 21-28.

20. Jain R and Sharma S, J Pharm Anal., 2012, 2(1), 56-61; DOI:10.1016/j.jpha.2011.09.013

21. Sharma D K, Mourya G L, Jhankal K K, Jones L A and Bhargava S K, Der Pharma Lett., 2012, 4(5), 708-714. 